\title{
An ethical dilemma
}

SIR-Since 1985 it has become apparent that an important correlate of successful infection with the AIDS (acquired immune deficiency syndrome) virus is an interaction of virus genes with the lymphocyte genes regulating the switch in growth (G0/G1 transition) necessary for resting lymphocytes to enter the cell cycle.

Optimal progress in medical research depends on communication and collaboration between researchers who, at the same time, are competing with each other for increasingly scarce research funds. If the collaboration between two researchers is symmetrical ('tit-for-tat'), then both researchers should benefit and medical research should progress optimally. But perfect symmetry is hard to attain. Thus, a researcher becomes aware that collaboration may help another researcher who may then gain an advantage. This communication/competition paradox may be starkly evident in the case of researchers who, while trying to optimize progress towards the cure of AIDS, are also trying to optimize their own research funding.

In the summer of 1985, after studying the lymphocyte growth switch for more than 20 years, I reported the successful application of a novel cloning strategy to the first preparation of a human lymphocyte cDNA library likely to be enriched in G0/G1 switch genes'. I was not surprised to be approached shortly afterwards by several laboratories engaged in AIDS-related research (I.C.Y. Chen, UCLA; W.A. Haseltine, Harvard; D. Baltimore, MIT), with requests for samples of my recombinants. I responded promptly to these requests. With small grants from the American Foundation for AIDS Research and the Leukaemia Research Fund (Toronto) I continued to isolate and characterize more recombinants from the library. In the intervening two years, no papers reporting the preparation of a similar library from lymphocytes have appeared. This also is not surprising because success in library preparation requires the coordination of specialized skills both in the culture of human lymphocytes and in recombinant DNA technology.

Now we come to the ethical dilemma. I recently submitted grant applications to three major funding organizations $\mathrm{NIH}$, MRC-Canada, NCI-Canada). In all of these I included the following sentence: "In view of the seriousness of the AIDS epidemic, it would have been most unethical to have delayed distributing our recombinants while awaiting funds for their study in our own laboratory."

All three applications were rejected. The following major criticism by the committee which reviewed one of the applications (NCI-Canada) is, I believe, not untypical of the attitude of many who sit on such committees: "It was noted that the applicant had already sent his potentially interesting clones to several large laboratories. There was concern that much of the interesting work would be done by these laboratories instead of by the applicant himself."

So there we have it. Altruistic conduct in research, even in the case of a matter so serious as AIDS, does not appear to be appreciated by the hard-nosed individuals who sit on grant review committees. I now have many more recombinants at a stage where they can be distributed to others in the AIDS-research community. Have I learned my lesson? Do I hold on to them and refuse to respond to future requests for samples? How many other researchers have valuable recombinants which they are not prepared to make available to other AIDS researchers?

In my case there is no ethical dilemma. The new recombinants (unpatented) will be sent promptly and without charge to assist any relevant investigation in medical research. The matter, however, raises the larger issue encapsulated in the phrase, "the communication/competition paradox". Have the organizations funding medical research seriously considered suggestions for modifying their procedures in order to reduce the intensity of competition and encourage communication and collaboration between researchers? The modern system of research funding, established immediately after the Second World War, has been very successful. But the positive role of competition in this success has been questioned ${ }^{2}$. Would progress in medical research have been even more spectacular if research funding were organized differently? It has been argued that the present system promotes patterns of conduct among researchers that impede progress ${ }^{3-5}$. Numerous suggestions for reforms have been made ${ }^{3-6}$. But there are few indications that the funding bodies can be shifted from their complacency. Meanwhile, the number of deaths from AIDS continues to rise exponentially? ${ }^{7}$. The cost of the management of just one AIDS patient (approximately $\$ 100,000$ ) would keep an average AIDS research laboratory operational for a whole year.

Department of Biochemistry,

Queen's University,

Kingston, Canada K7L $3 N 6$

1. Forsdyke, D.R. Biochem. biophys. Res. Commun. 129 619-625 (1985)

2. Ubell, R. Nature 294, 28 (1981)

3. Alberts, B.M Cell 41, 337 $\cdots 338(1985)$

4. Osmond, D.H. J. Neurobiol. 14, 95-112 (1983).

Forsdyke, D.R. Med. Hypothesis 11, 141-145; 147-156 (1983)

Forsdyke, D.R. Nature 312, 587 (1984)

7. Rees, M. Nature 326, 343-345 (1987).

\section{Japanese whaling}

SIR-David Swinbanks' account of Japanese concern about the ban on whaling is well-balanced ${ }^{1}$ but one aspect was not mentioned.

Small-scale whalers in Japan operating in coastal waters argue that they have the same "aboriginal subsistence" whaling culture as do Eskimos and that the International Whaling Commission should exempt them from the imposed moratorium $^{2}$. To me, the logic of this seems farfetched for at least the following reasons. (1) Although whale meat is an important component in the daily diet of Eskimos ${ }^{3}$, it at present constitutes only 2 per cent of animal protein in the daily intake of Japanese according to the Japan Whaling Association ${ }^{4}$

(2) Whereas the Eskimos are still maintaining their traditional method of catching whales by an open whale boat (called umiak) consisting of a wooden frame covered with hide and propelled with broad paddles, the Japanese transformed their traditional methods of net whaling to industrial whaling in $1899^{5.6}$.

(3) For Eskimos living in the Arctic environment, which is limited in numbers of natural flora and fauna, whaling is a necessity for survival. But this necessity does not now exist for Japanese. Whaling would have been a necessity in past centuries when Japanese refrained from eating other kinds of meat. But contemporary industrialized Japanese society is hardly dependent on whale meat for survival.

Sachi SRI Kantha

Laboratory of Marine Biochemistry,

University of Tokyo,

Bunkyo, Tokyo 113,

Japan

1. Nature 326, 732 (1987)

Sato, S. The Daily Yomiuri (Tokyo) 9 May, 1987, p.7.

Bang. H.O., Dyerberg. J. \& Hjørne. N. Acta med scand. 200, 69-73, (1976)

4. Living with Whales (Japan Whaling Association, Tokyo, 1980)

5. Man, Whales and the Sea p.9. (Japan Whaling Association, Tokyo).

A Brief Whaling Perspective, p.16 (Japan Whaling Association, Tokyo, 1986).

\section{Litigious challenge}

SIR-I noticed with interest the recent contributions on the possible connection between cooking in aluminium vessels and the onset of Alzheimer's disease.

It will be interesting to see what happens when the first American lawyer realizes that Alzheimer's patients may have been taking aluminium in quite large quantities in antacid preparations.

Department of Chemistry and

D.A.H. TAYLOR

Applied Chemistry,

University of Natal,

King George $V$ Avenue,

Durban 4001,

South Africa 